\title{
Digitalization and study of graphic disciplines in English: current state and prospects
}

\author{
Elena Fisunova* \\ Don State Technical University, 344002, Rostov-on-Don, Russia
}

\begin{abstract}
The article discusses the possibility of effective use of various software in the study of graphic disciplines in English in order to compare the quality of classical teaching and learning using various graphic packages in the study of geometric-graphic disciplines in English and its convergence with science. The ways of using graphic editors for training specialists in various industries are described. The teaching methodology is considered, which allows a creative approach to the implementation of two-dimensional and three-dimensional objects. The article describes the use of various software products in the modernized laboratories of "Computer prototyping and reverse engineering of high complexity." In this regard, the study of digitalization of graphic education in English and its social consequences seems to be a very relevant area of research.
\end{abstract}

\section{Introduction}

In modern society, special importance is attached to the informatization of education. For today's young generation, when teaching, everything that is displayed on a computer monitor is much closer than in a text version in various sources of information. An important place in the development of spatial and logical thinking of students is occupied by the use of information technologies [1] in teaching graphic disciplines in English, which allows us to cover a larger volume of theoretical training.

However, it should be noted that there are acute problems associated with the teaching staff who do not want to change the classical methodology of teaching disciplines for the presentation of theoretical material using new modern technologies, the Internet, online training, and the creation of online courses. And the demand of society is completely different, so today the main task of modern higher education is to widely attract highly qualified teachers who are familiar with modern information technologies to train specialists in various fields of the country's economy. Today digitalization has affected all aspects of the university's activities. To solve the urgent problems facing the flagship university [2], the post of vice-rector for strategic and digital development has been introduced. The main activities [3] of which are:

- Development and implementation of long-term and short-term plans and projects of strategic development of the university, implementation of development programs,

\footnotetext{
* Corresponding author: fis62@mail.ru
} 
search for new directions and schemes for their implementation, optimization of the main activities of the university;

- Development of the concept of development and modernization of the property complex of the university and mechanisms for its implementation;

- Ensuring the development of additional education activities and advanced training of students, university employees and other persons;

- The introduction of modern digital technologies in all areas of the university's activities, the development and implementation of digital transformation projects and coordination with state digital platforms and projects, the improvement of information and technical support of the university and the use of modern software and hardware systems;

- Ensuring information and complex security of the university, personnel, financial information and a number of other issues.

Modern digital programs have been introduced that allow monitoring the quality of training of students by both external and internal consumers, monitoring an effective contract for the teaching staff, the content of the portfolio of students and teachers, electronic grade books, statements, electronic work books and more. At the same time, broadband Internet is spreading, and massive online training courses are being used, which are available today to everyone on a variety of topics. As access to digital technology expanded, educators began to use it more often for solving educational problems. This interest is stimulated, among other things, by the implementation of the clauses of an effective contract that demonstrates the teacher's readiness for changes, the ability to recognize new things, maintain and disseminate effective forms and methods of educational work. The change in ideas about the place of digital technologies in engineering and graphic education was the creation of computer classes, which was the first step in the formation of a digital information environment. The purpose of this study is to comparatively analyze the quality of training students using two teaching methods: classical and using information technology.

\section{Basic theory}

In accordance with the Development Program of DSTU until 2030 in the laboratories "Computer prototyping and reverse engineering of high complexity" (Figure 1), laboratory classes are conducted on computers with installed software such as SIMENS NX, ANSIS, AutoCad, SolidWorks, KOMPAS and others. The use of graphic packages in teaching firstyear students of the university contributes to the formation of sustainable skills in the use of modern information technologies for the preparation of a modern $\neg$ specialist for various sectors of the region's economy. One of the benefits of computer-aided design and simulation is that it allows you to complete a design from concept to actual implementation on a computer, and then prototype in metal. Teaching students how to work in various software systems in English [4] allows you to optimize the design in order to improve the performance, reduce the price, and identify the design flaw in assembly with other parts.

The electronic model plays the role of the primary source for all stages of the product life cycle, is stored in the project database and provides a solution to engineering problems during design, production, operation and disposal. The use of modeling tools to demonstrate [5] algorithms for shaping surfaces contributes to a better perception of educational information and the acquisition of skills in creating electronic models of objects. Students during their studies in the laboratories of "Computer prototyping and reverse engineering of high complexity" acquire the skills of two-dimensional and threedimensional modeling in accordance with the working programs of graphic disciplines. 


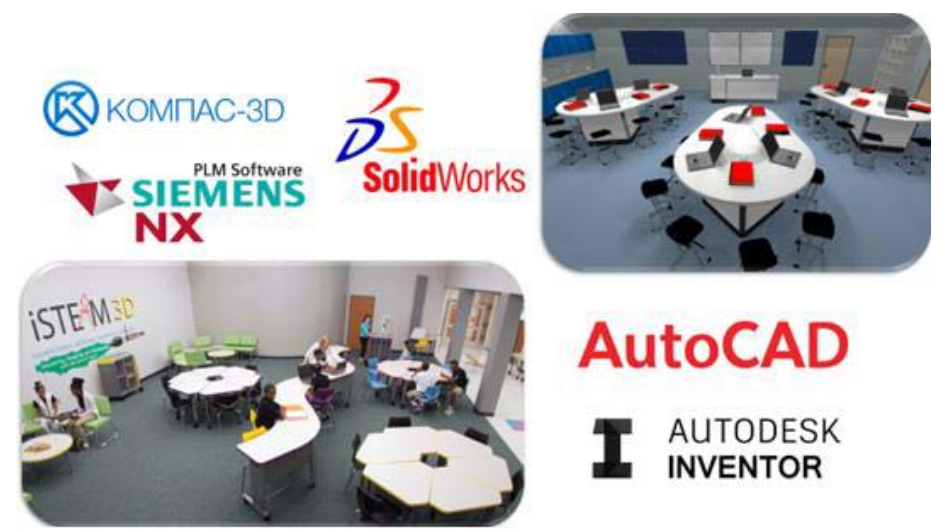

Fig. 1. Laboratory of Computer Prototyping and Reverse Engineering of High Complexity

Recently, the development of digital prototyping and the introduction of $3 \mathrm{D}$ simulators into the educational process are increasingly used [6]. One of the examples of such work is the creation of a parametric model of the assembly "Safety valve" (Figure 2.). This simulator allows students to create a digital prototype based on the dimensions of a real product and develop sketches for it, working drawings using 3D modeling. Work in this direction has created its own library of assembly units. The presence of such simulators provides a new vector for the introduction of information technologies into the educational process.

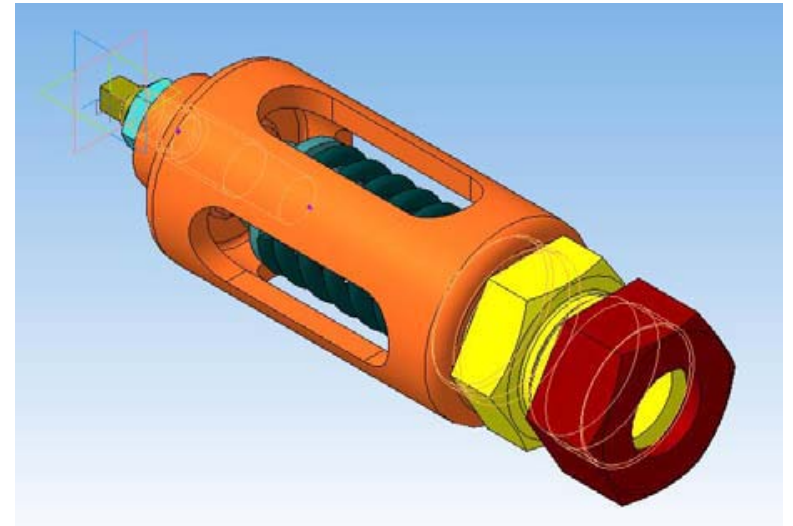

Fig. 2. Model 3-D Relief Valve Trainer

New requirements are being put forward in the need to increase graphic literacy in engineering and design activities, since a modern design engineer must be fluent in engineering graphics, be able to model and design objects, be free to navigate in a variety of graphic software packages, be able to rebuild and independently master new things in rapidly changing world of engineering technology. The use of modern technologies in the system of higher education [8] provides new opportunities for enhancing the process of professional graphic training of students.

The assembly of a three-dimensional model that combines models of parts, standard products (Figure 3), called assembly components, carries information about the relative position of the components and the relationships between the parameters of their elements. Assembly design [9] can be done in three ways: bottom-up, top-down, and mixed. 

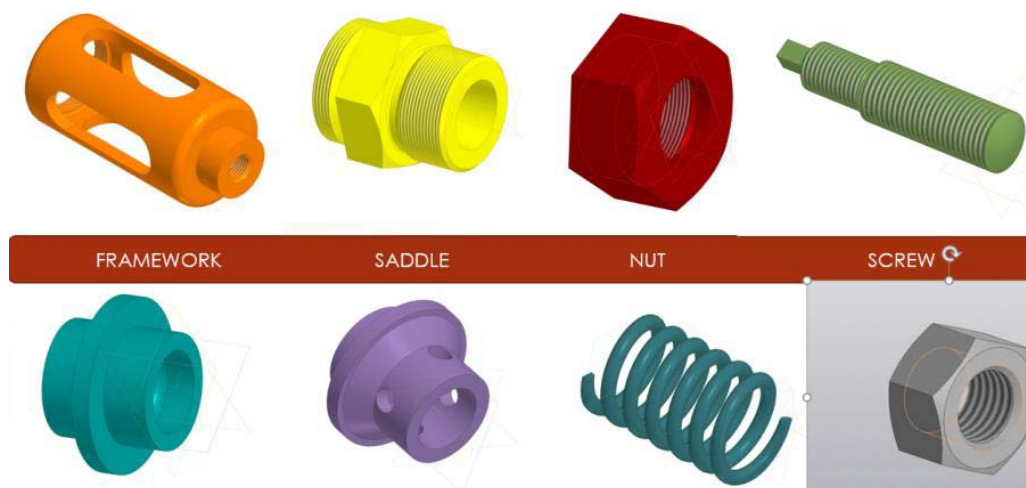

NUT

SCREW 9

SUPPORT VALVE

Fig. 3. Models of parts-assembly components

The design of the safety valve is carried out from the bottom up, in which all the components of the assembly are first created (Figure 3), then they are assembled. The components are inserted into the assembly, and then the required mates are established between them. While simple, this order only applies when creating assemblies with a small number of parts. This is because the shape and size of parts in assemblies are always related.

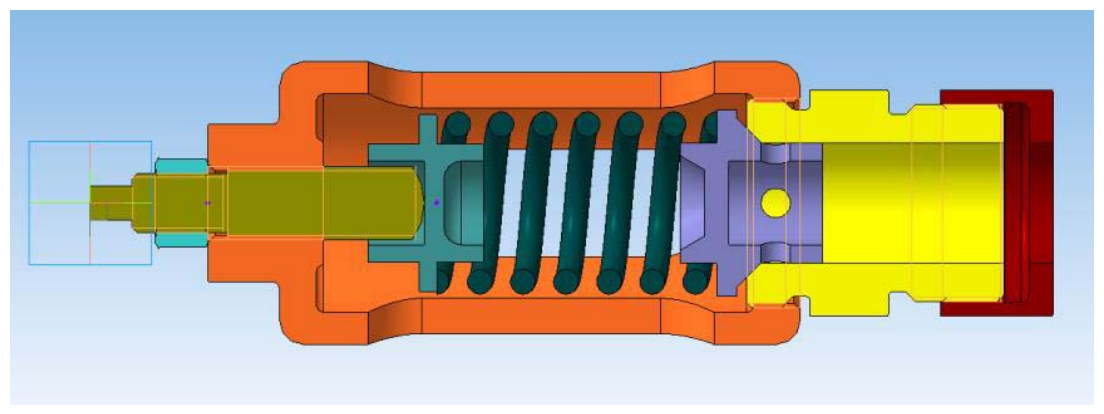

Fig. 4. Cutaway safety valve model

To model parts, it is necessary to accurately represent their relative position, shape, calculate and remember the dimensions of some parts in order to set the dimensions of other parts depending on them (Figure 4).

\section{Prospects for the use of digital technologies}

Many intelligent teaching systems include an open student model, which involves the collection of information about the student's achievements, his emotional state, about his prejudices. This model allows the student to see himself from the outside, analyze the learning outcomes, identify difficulties and outline ways to overcome them, and also contains a lot of evidence that can be used by the teacher for dynamic improvement in work. The information collected helps teachers evaluate the results of educational work, taking into account the characteristics of the curriculum being mastered. Teachers, working online personal tutors [10] monitor the progress of educational work, guide it and identify emerging problems. 
Currently, artificial intelligence is widely used and demonstrates the successful application of artificial intelligence in the educational process, a network learning environment has been created that dynamically generates interactive teaching materials in graphic disciplines, adapted to the goals, preferences, capabilities and knowledge of the student. The student accesses the course through a standard web browser. In the course of educational work, the student interactively solves problems in graphic disciplines in English.

Of interest are the technologies of artificial intelligence in the education of the student's movement according to the educational program of the discipline being studied. The transition from one block to another is associated with the successful mastering of the next topic by the student. The goal of training is set in the form of several intermediate blocks that contain a set of topics, the development of which is provided for by the educational program. Learning begins with assessment. Based on its results, a student's profile is built and a program block is selected that most accurately describes the current state of his knowledge [11]. As you progress through the material, the profile is constantly updated. An adaptive system for managing educational work allows you to abandon the specified templates and builds an individual sequence of presentation - a trajectory for the presentation of educational material, based on data on the student's actual knowledge and his individual characteristics accumulated during training. The system assesses which topics the student is best prepared to master and generates appropriate recommendations for the teacher or the student himself in the case of self-study.

There is a diverse set of tools for monitoring and managing the educational process. Creation of a website on a social network, where students can ask questions that arise in solving educational problems and doing homework in graphic disciplines, and get answers. The peculiarity of this work is that students receive verified answers. In addition, the site helps you find the correct answers yourself. A tool for intelligent processing of educational materials has been developed [12]. Using this tool, specialists automatically form a package of educational materials from various sources that fully meets the requirements of a specific educational program prepared by a teacher, taking into account the specifics of areas. With the help of the application, anyone can transform traditional textbooks and teaching aids into concise and concise teaching materials themselves. Such materials contain educational information and test questions to check its assimilation. This set of curricula focuses on the use of blended learning. It combines traditional teaching materials and software [14]. Study materials are adapted to the interests of students, and all proposed tasks are practiceoriented. The combination of traditional teaching materials with an intelligent teaching system allows for the widespread use of formative assessment and problem-oriented learning work. Artificial intelligence technologies in the education of a bot in small groups and individual educational work allow the teacher to personalize the educational work, to pay attention to everyone.

Created avatars (text, voice and video) are offered, which act as a personal tutor. Communication with the avatar takes place via Skype. A personal tutor is able to analyze the mood and emotional state of the interviewee. During the video chat, Skype is used, with the help of a webcam, the system processes facial expressions, features of the sound of the voice and the turns of speech used by the interviewee, and on this basis offers recommendations for correcting their statements and behavior. Thus, the student can prepare, for example, for the upcoming differential test or exam. The learning platform has become promising in the field of intelligent learning systems. The intelligent learning system combines advances in artificial intelligence and computer-based learning. The creation of a research laboratory for artificial intelligence, which will develop the basic algorithms for the detailed allocation of individual components of learning outcomes, learning objectives, and there is the prospect of digitalization in education. 


\section{Research results}

Research has been carried out to compare the performance of students studying graphic disciplines in educational programs using digital technologies and educational programs without their use. The objects of the research are students of the Don State Technical University, aged 18 to 20 years. The sample is 90 people. The subject of the research is the quality of training students in the discipline "Engineering and Computer Graphics". Research method - theoretical analysis of the literature on the problem under study, comparison, interpretation, methods of mathematical data processing.

To get a more detailed picture of the results of the experiment, all participants were divided into groups according to the criterion of their academic performance. As a result, there were three pairs of groups: high-performing students, intermediate students, and lowperforming students studying in various fields. In turn, each pair is divided into a group whose training was carried out using digital technologies in the discipline "Engineering and Computer Graphics", and a group that did not use digital technologies in this discipline. As a result, six groups were studied, each of which had 15 students.

This division was carried out to compare the impact of changes in teaching, without changing the content of the discipline program, on each of the groups of students. After completing the training, we checked how the maximum use of computer programs influenced the development of the material of the graphic discipline by students with different levels of training. Within a few days, all students passed the final electronic Internet testing. The test consisted of 40 questions, each of which offered a choice of answers. Each participant was given time to take the test for testing, and within 90 minutes, as they answered the questions, the students showed their knowledge. After completing testing, the program automatically displayed the results of Internet testing. The test result was evaluated on a 100-point scale. Test questions were similar for all students.

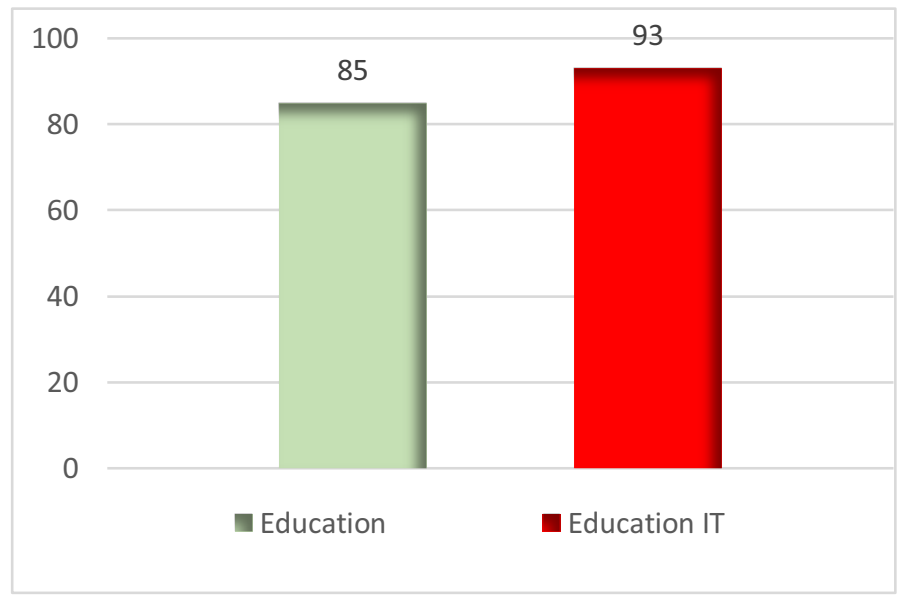

Fig. 5. Test results of a group of students who received "excellent"

After analysis, several charts display the results of the experiment for each group of students. Analyzed the points scored by students with high academic performance. We calculated the average value for the group of "excellent students" who studied without the use of digital technologies, and for the group of "excellent students" who studied according to the program using various software. It was found that the average score of a group of students with high academic performance, who studied in a program that does not include modern digital technologies, showed an average result of 85 points, and a group with a training program that includes the use of digital technologies, showed a result of 93 points. 
(Figure 5). From the analysis of the results, we can see a significant preponderance in favor of the second group with a training program using digital technologies. Consider the test scores of average students.

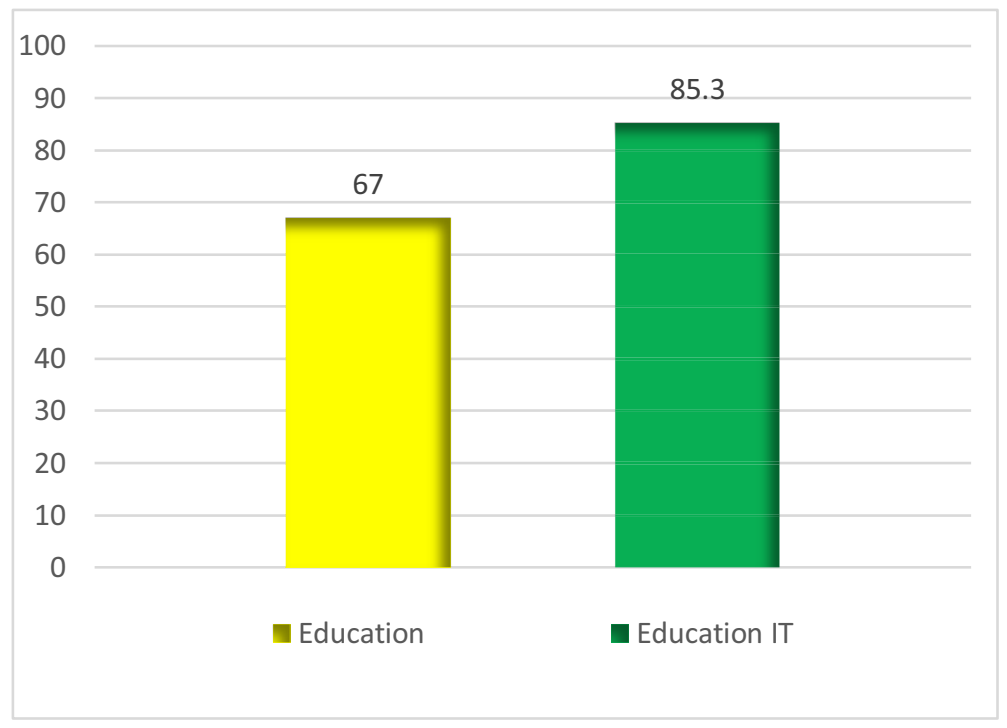

Fig. 6. Test results of a group of students who received "good"

The average score of the group of students with average academic performance, who studied according to the program without the use of digital technologies, showed a result of 67 points, and the group teaching according to the program using digitalization - 85.3 points (Figure 6).

The group of students with low academic performance who studied according to the program without the use of information technology showed an average result of 50.7 points and the group with the training program using digitalization - 65.2 points (Figure 7).

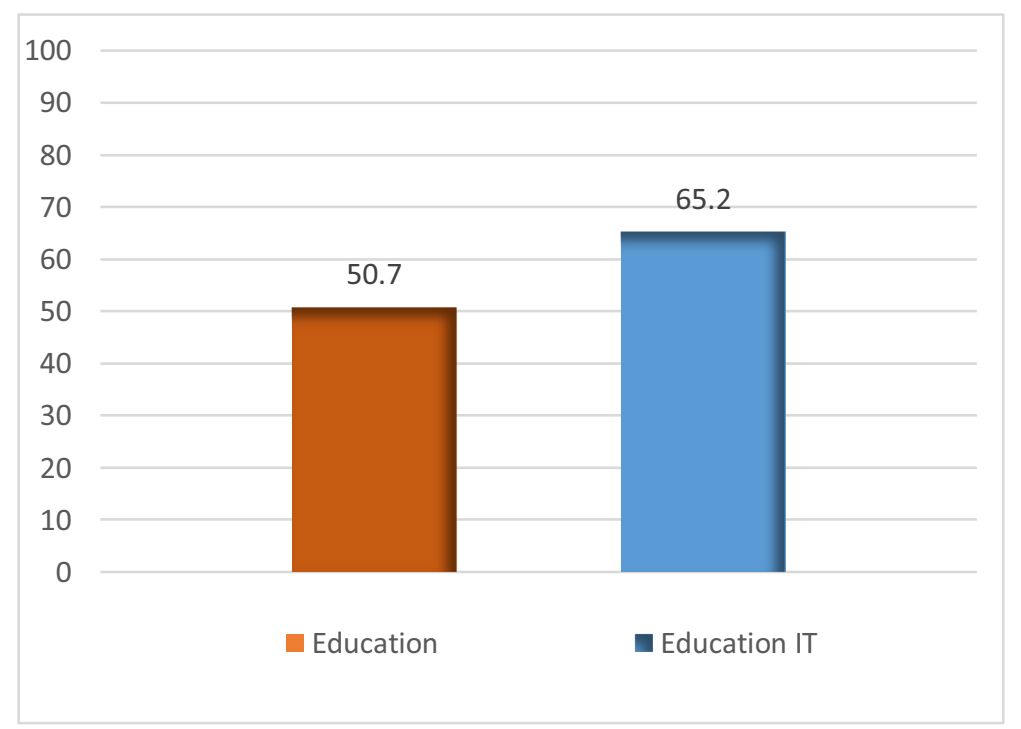

Fig. 7. Results of Internet testing of a group of students who received "satisfactory" 
Summarizing the data for three categories of students (Figure 8), we can safely say that with the increased interest of students in the study of graphic disciplines using information technology in English, the relevance of the transition to teaching disciplines using various graphic packages showed high-quality results and increased the percentage of students' progress.

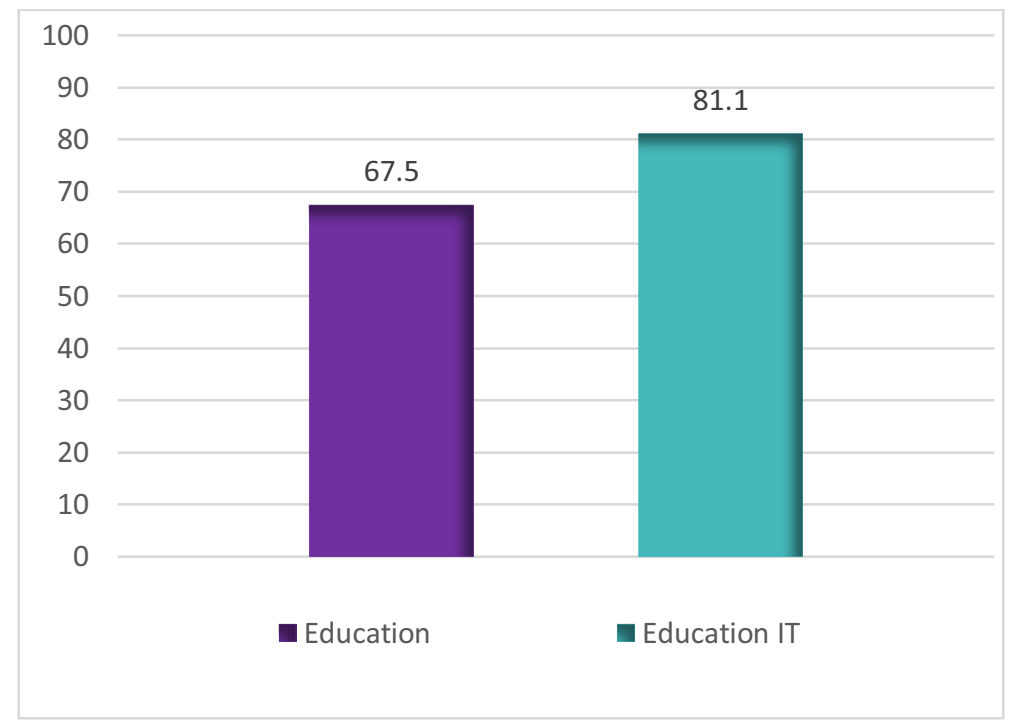

Fig. 8. Results of Internet testing to determine the quality of training of students

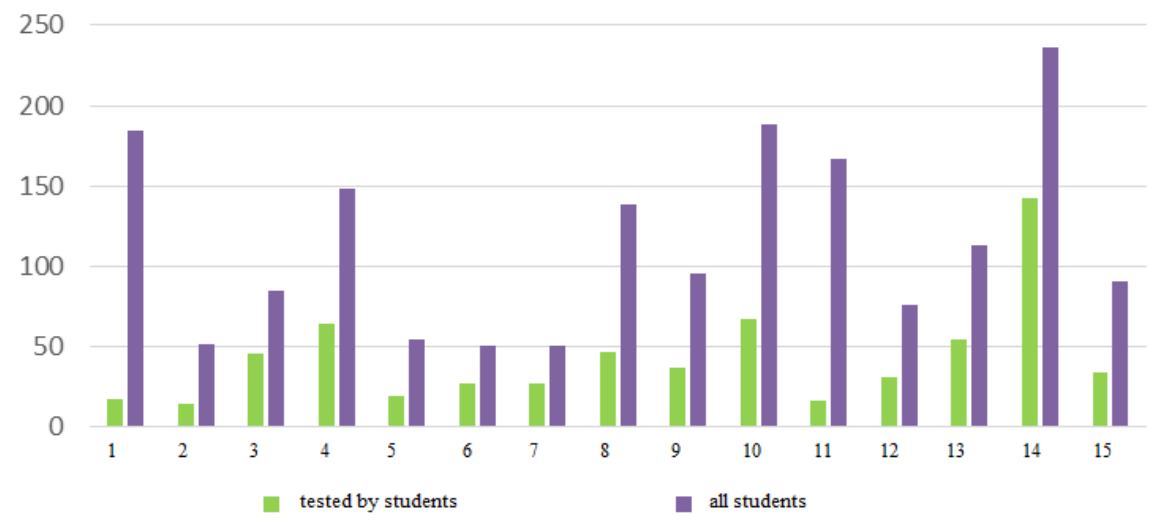

Fig. 9. Results of Internet testing to determine the quality of training of students by the number of tested groups

Figure 9 shows a diagram showing the results of the number of groups in which an objective final assessment of knowledge was carried out using Internet testing.

In addition, an analysis was made of the number of students who passed the final Internet testing to the possible number of participants in the experiment (Figure 10), in some groups, as can be seen from the diagram, there is a very low percentage of participants, which is explained by the reluctance of some representatives of the teaching staff to use modern information technologies in teaching.

The main problems of digitalization in education are identified: the dehumanization of educational, and then all other social relations, the possible deepening of the crisis of 
people's intellectual culture, their ability to create, the growth of pragmatism and individualism based on the values of personal comfort and selfish consumption.

The prospects for the development of digitalization in the education system are outlined: instrumental equipment of educational institutions with high-quality software, information systems that provide access to educational resources, the introduction of information (distance) technologies, online learning, changing requirements for teachers and students, the formation of new organizational educational structures, inevitable changes in the usual forms and methods of teaching; value-semantic finding of harmonious unity with the best traditions of national education.

\section{Discussion}

These conclusions are aimed at solving practical issues related to the implementation of the state policy of digitalization in various spheres of public relations. They can contribute to the coordination of efforts of scientists, politicians, civil society institutions for the socioeconomic and cultural development of our society. The results obtained allow a more objective and meaningful approach to the fundamental problems of higher education. They are designed to stimulate the creation of new educational technologies based on the specifics of world techno-scientific processes.

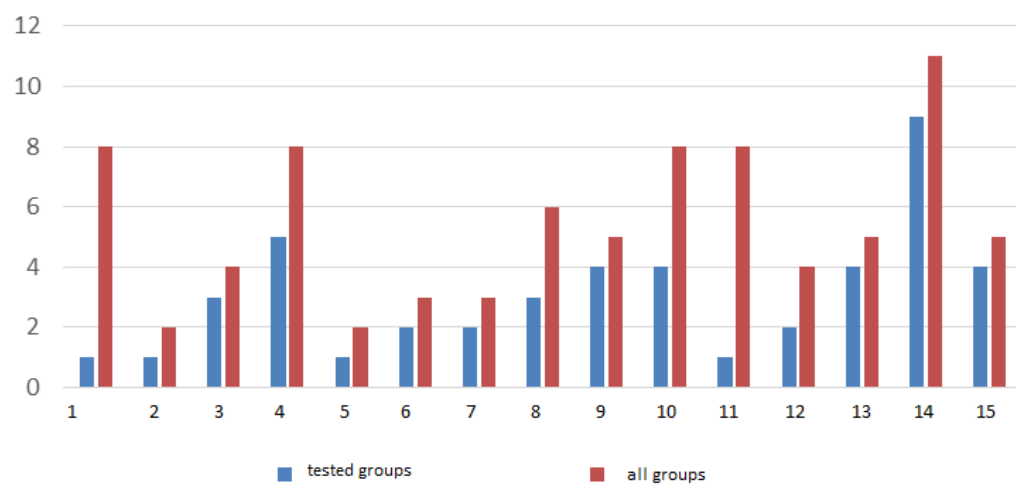

Fig. 10. Results of Internet testing to determine the quality of training of students by the number of tested students

\section{Conclusion}

The modernization of domestic higher education is inevitable; in the presence of innovations, it is not necessary to abandon the traditional educational technologies that have proven their effectiveness. The important role of innovative technologies in the formation of an effective educational environment in Russia is obvious, since their use can potentially contribute to improving the assimilation of knowledge, the development of students' creative abilities, the formation of readiness for their application of theoretical knowledge in practice and independent thinking. Based on this, we can say that the use of innovative technologies in educational activities is a prerequisite for the training of high-quality specialists. It is necessary to take into account their specificity, presented by scientific analysis and the available experience in the practical transformation of the modern educational environment. The introduction of innovative methods, forms and means of teaching allows you to create a new strategy for vocational training in vocational education. 


\section{References}

1. T. Vlasova, E. Krasnova, E3S Web of Conferenses 210, 18012 (2020).

2. M. Sergeeva, V. Ermakov, E. Chirkova, N. Klimovskikh, E. Krasnova, B. Alieva, M Asilderova, Modern Journal of Language Teaching Methods 9 (1), 405-410 (2019).

3. T. Vlasova, B. Meskhi, S. Smirnov, BPiKAinSM, 59-85 (2018).

4. E. Krasnova, E. Laskina, E. Molsova, E. Velichko, $5^{\text {th }}$ International Multidisciplinary scientific Conference on Social Sciences and Arts SGEM 2018, Conference proceedings, 427-434 (2018).

5. T. Vlasova, E. Krasnova, V. Abraukhova, N. Safontseva, Journal of Social Studies Education Research 9 (1), 76-88 (2018)

6. G. Morrison, S. Ross, J. Kemp, H. Kalman, Designing effective instruction: Applications of instructional design (New York, NY: Wiley, 2010).

7. A. Gutnick, M. Robb, L. Takeuchi, J. Kotler, Always Connected: The New Digital Media Habits of Young Children (New York, 2011).

8. L. Stosic, IJCRSEE 1 (2), (2013).

9. B. Cvetkovihc, L. Stosic, A. Belousova, (2018). https://www.scopus.com /inward/record.url?eid=2-s2.0-85071050109\&partnerID=40\&md5=c942806b1 f341d0c4c1be814dfcca8fa

10. G. Klinkov, M. Rodionov, N. Bakharev, E. Vezetiu, E. Vovk, Amazonia Investiga 9 (26), 16 (2020).

11. Yu. Lia, Z. Xiaoning, Procedia Computer Science +129 (2018). https://reader. elsevier.com/reader/sd/pii/S1877050918303223?token=50EC20B3EACC90CD2E 7FC88D4E2DA4BB771B63728117CF84485F2C1E8736A27BD2C4CA5BF A4331AE1D0835987E5D7F0B [Google Scholar]

12. O. Akay, I. Tsarevskaia, I. Shcherbakova, N. Krivtsova, (2019). https://www. scopus.com/inward/record.url?eid=2-s2.0-85076545461\&partnerID=40\&md5= 509bcaa6b8eb0c56fca1dd000b09f154

13. N. Gafiatulina, L. Makadey, I. Gluzman, A. Lozhechkina, L. Volkova, A. Bandurin, (2019). https://www.scopus.com/inward/record.url?eid=2s2.085074113588\&partnerID $=40 \& \mathrm{md} 5=58 \mathrm{f} 40 \mathrm{c} 5 \mathrm{e} 30 \mathrm{~b} 6 \mathrm{aec} 00 \mathrm{c} 185 \mathrm{~b} 9543 \mathrm{e} 6 \mathrm{c} 07 \mathrm{f}$

14. T. Olenich, Y. Maslova, T. Klimenko, V. Zakharova, A. Astashova, K. Vodenko, (2019). https://www.scopus.com/inward/record.url?eid=2-s2.0-85074330578 \&partnerID=40\&md5=63d5ab69699df49deff0acedef3d4983

15. Passport of the Federal project "Digital educational environment" of the Russian Federation http://www.edu54.ru/upload/files/2016\%B0.pdf 